\title{
A NEW LABORATORY COLONIZATION OF AEDES AEGYPTI AFTER REEMERGENCE AND UNSUCCESSFUL ERADICATION IN ST. AUGUSTINE, FLORIDA
}

\author{
RUI-DE XUE, CHRISTOPHER S. BIBBS, DANIEL DIXON, \\ AND DENA AUTRY \\ Anastasia Mosquito Control District, 120 EOC Drive, St. Augustine, FL 32092 \\ Guest Editor: Whitney Qualls
}

\begin{abstract}
After unsuccessful eradication attempts against Aedes aegypti (L.) following a sudden re-emergence in St. Augustine, Florida in early 2016; a new locally acquired colony strain of Ae. aegypti was established at the Anastasia Mosquito Control District (AMCD) in June 2017. Aedes aegypti adults were maintained in cages at the AMCD insectary. Larval and adult mosquitoes were collected from downtown St. Augustine, Florida. Female mosquitoes at 5-7 days old were fed upon the exposed forearm of human volunteers in the $1^{\text {st }}$ and $2^{\text {nd }}$ generations. Mating was observed in a large cage and confirmed with eggs deposited on wet filter paper in ovicups. Over $90 \%$ egg hatch was observed in the laboratory. The new colony strain of Ae. aegypti has been cataloged at the USDA, Center for Medical, Agricultural, and Veterinary Entomology facility in Gainesville, FL and is being used to further research and control this species across North Florida.
\end{abstract}

Key Words: Aedes aegypti, colonization, eggs, blood meal, integrated mosquito management

Aedes aegypti (Linn.) is a major vector of dengue virus, chikungunya virus, yellow fever virus, and Zika virus. Before the mid1980's Ae. aegypti was the primary containerinhabiting vector mosquitoes in St. Augustine and throughout northeastern Florida (Betts 1994). After the introduction of Aedes albopictus (Skuse) in the mid-1980's (Smith et al. 1990), Ae. aegypti gradually disappeared from Northern and Northeastern Florida (O'Meara et al. 1995).

Saint Augustine, one of the oldest cities in North America, is a tourist attraction in Northeastern Florida; hosting a significant number of temporary residents and vacation-travelers, creating an environment susceptible to travel-related cases of dengue, chikungunya, yellow fever, and Zika (Smith et al. 2018). Consequently, surveillance and control of Ae. aegypti is a cornerstone for local public health and mosquito control programs.

In 2011, a resurgence of Ae. aegypti was detected in the urban areas of Jacksonville and Northeastern Florida (Wright et al 2015). St. Johns County shares borders with the city of Jacksonville, FL (Duval County), therefore leading to increased surveillance by Anastasia Mosquito Control District (AMCD) of container-inhabiting mosquitoes since 2011 in order to detect the presence of Ae. aegypti in St. Augustine. On 15 of Feb, 2016, a resurgent population of larval Ae. aegypti was collected for the first time from used tires and cisterns in downtown St. Augustine, FL. In response to this detection, AMCD launched a city-wide surveillance grid and eradication program focused on the downtown area surrounding the positive sample sites. As a result, 9 hot spots were located in the surrounding area by BG traps with BG lures (Biogents AG, Regensburg, Germany). These hotspots inflated to cover all of the downtown municipality by July 2016.

From April 2016 to August 2017, an eradication survey program was developed for the attempted eradication of Ae. aegypti from downtown St. Augustine. Initial program elements relied on traditional methods through systematic visitation of all streets, businesses, and residences by personnel in combination with integrated mosquito management for inspection, source reduction, treatment when hotspots were detected, and 
education of all local residents. Downtown St. Augustine was divided into five routes and assigned two technicians per route (1 from the Department of Health and 1 from AMCD) for inspection, education, and control of mosquitoes on a weekly basis.

In the beginning of the eradication survey, a few adult Ae. aegypti were collected from George Street and Spanish Street in the heart of downtown St. Augustine. These two thoroughfares host tourist attractions and historic preservations, such as the oldest schoolhouse, local businesses, churches, and semi-enclosed courtyards of Spanish architecture. All areas of interest were surveilled using manual source reduction, sampling, and overnight trapping with BG traps combined with BG lure. Relatively few adults were captured in traps, however a high number of human landings were confirmed to be $A e$. aegypti from the BG trap sites, likely due to the traps failing to compete against natural human odors from numerous visitors and residents along the affected streets (Owino et al 2014). To overcome the weaker long-range attraction of the $\mathrm{BG}$ lure, $\mathrm{CO}_{2}$ was added in combination with BG lure leading to an $80 \%$ increase in female Ae. aegypti. This result was similar to a study by De Azara, et al. (2013) using BG lure in combination with $\mathrm{CO}_{2}$ for increased collection of $A e$. aegypti by BG trap in Manaus, Brazil.

The resurgent Ae. aegypti population spread and was detected by dual baited BG traps outside of St. Augustine city limits and many areas of St. Johns County, Florida in 2017. Concomitantly, the eradication of $A e$. aegypti was considered to have failed. Since 2018, AMCD collaborated with USDA/ CMAVE, University of Florida, MosquitoMate, and SpringStar to explore and adopt novel IPM strategies and tools to control $A e$. aegypti, such as SIT (sterile insect technique) male release, release of Wolbachia-infected male mosquitoes, and mass deployment of Autocidal Gravid Oviposition traps for targeted control of Ae. aegypti.

Alongside the eradication survey taking place in 2016, AMCD was collaborating with University of Florida and USDA / CMAVE to release irradiated 1952 Orlando strain Ae. ae- gypti within St. Augustine Beach for control of reemerged Ae. aegypti mosquitoes. The experimental control method generated concerns from local residents about the release and infestation of the Orlando strain into St. Augustine. Therefore, it was a critically important objective to establish a local colony of Ae. aegypti for public acceptance and support.

In June 2017, mosquito larvae were aspirated from a variety of containers: bromeliads, tires, stagnant pools, cisterns, and other artificial water impoundments throughout downtown St. Augustine, FL. The larvae were transported to the insectaries at AMCD via Nasco WHIRL-PAK sample bags. Larvae were transferred into $4 \mathrm{oz}$ soufflé cups and placed inside a receptacle with a saturated sugar water cotton ball for newly emerged adults. The soufflé cups were given 0.1 gram of ground cat food for larval consumption. Every day the collected larvae were monitored for pupation and adult emergence. Emerged adults were removed, sorted based on species and sex, and transferred to rearing cages (Bug Dorm 2, BioQuip, Rancho, Dominguez, CA 90220) using mouth aspirators.

Within the first generation, adult female mosquitoes were not receptive to blood meals offered as part of standard operating procedure at AMCD, therefore a human volunteer exposed their forearm to feed adult mosquitoes until engorgement. An oviposition source (vol. $0.5 \mathrm{~L}$ ) with an ovistrip was placed in the cage $(30.5 \mathrm{~cm} \mathrm{~W} \mathrm{x} 45.7 \mathrm{~cm} \mathrm{~L}$, BioQuip), but no eggs were collected after 5 days. A second attempt to collect eggs, involved 45 blood engorged females and 50 males transferred to a larger, collapsible rearing cage for mating and oviposition (Mega View Science, 60 × 60 × $60 \mathrm{~cm}$ ). A black oviposition container $(1 \mathrm{~L})$ with ovistrip and reverse osmosis water $(250 \mathrm{~mL})$ was placed into the cage for egg collection. Within 3 days a total of 2,050 eggs were collected from the 50 engorged female mosquitoes after multiple blood meals. The eggs (ca. $98 \%$ ) were hatched in a cup (1 L) of osmosis water $(200 \mathrm{~mL})$. After the F1 generation, the $\mathrm{F} 2$ generation of $A e$. aegypti adults were 
weened onto blood meals used as part of AMCD's standard insectary procedures. Aedes aegypti colonies were fed on $10 \%$ sucrose soln. ad. libitum from a $150 \mathrm{~mL}$ receptacle and cotton wick. The colony was maintained in the AMCD insectary at $80 \% \mathrm{RH}$ and $26^{\circ} \mathrm{C}$ in a 14:10 L:D photoperiod. Adult female mosquitoes were provided blood weekly via restricted live chicken (AMCD animal care manual approved in 2005), and oviposition substrates were collected 72-96 hours post blood meal.

Observations during the establishment of the Ae. aegypti AMCD strain led to a hypothesis that newly emerged male and female adult mosquitoes lacked the appropriate space in the initial colony cage, as there were no observations of mating activity. The female mosquitoes would feed, but not on live chickens. After transferring male and female mosquitoes to the larger cage $(45.7 \mathrm{~cm}$ L x $30.5 \mathrm{~cm} \mathrm{W \times 30.5} \mathrm{cm} \mathrm{H),} \mathrm{males} \mathrm{and} \mathrm{fe-}$ males were observed engaging in courtship and successfully copulating. The gravid female mosquitoes subsequently oviposited on an ovistrip in the containers provided. The $2^{\text {nd }}$ generation of $A e$. aegypti were weened by first offering a human arm, but rather than allowing to feed, mosquitoes were left in an active host-seeking state and the chicken blood meal was provided. This process was repeated until mosquitoes fed without the need for a human volunteer. The established colony actively feeds on restricted live chicken and lays sufficient eggs to maintain itself.

To facilitate the new control methods and to establish trust and understanding among St. Johns County residents, the new local strain of Ae. aegypti mosquitoes needed to be scaled up to meet the research and production needs. Consequently, the colony was transferred to our collaborators, USDA/ Center for Medical, Agricultural, and Veterinary Entomology, Gainesville, FL and the University of Florida for mass production and SIT treatment. In return, the SIT treated mosquitoes are returned to St. Augustine to release against the naturalized population of Ae. aegypti.

\section{REFERENCES CITED}

Betts RR. 1994. Aedes albopictus and Aedes aegypti: Species domination in St. Johns County. J Florida Mosq Control Assoc 65:17-19.

De Azara TM, Degener CM, Roque RA, Geier M, Wiras AE. 2013. The impact of CO2 on collection of Aedes aegypti (Linnaeus) and Culex quinquefasciatus Say by BG-Sentinel traps in Manaus, Brazil. Mem Inst Oswaldo Cruz 108:229-232.

O’Meara GF, Evans LF Jr, Gettman AD, Cuda JP. 1995. Spread of Aedes albopictus and decline of Aedes aegypti (Diptera: Culicidae) in Florida. J Med Entomol 32:554-562.

Owino EA, Sang R, Sole CL, Pirk C, Mbogo C, Torto B. 2014. Field evaluation of natural human odors and the biogent-synthetic lure in trapping Aedes aegypti, vector of dengue and chikungunya viruses in Kenya. Parasites Eं Vectors 7:451.

Smith JP, Loyless TM, Mulrennan JA Jr. 1990. An update on Aedes albopictus in Florida. J Am Mosq Control Assoc 6:318-320.

Smith M, Dixon D, Bibbs CS, Autry D, Xue RD. 2018. Diel patterns of Aedes aegypti (Diptera: Culicidae) after resurgence in St. Augustine, Florida as collected by a mechanical rotator trap. J Vector Ecology 44:201204.

Wright JA, Larson RT, Richardson AG, Cote NM, Stoops CA, Clark M, Obenauer PJ. 2015. Comparison of BG-Sentinel trap and oviposition cups for Aedes aegypti and Aedes albopictus surveillance in Jacksonville, Florida.. J Am Mosq Control Assoc 31:26-31. 